\title{
VIBRATIONS AND STABILITY OF MOTION OF A MAGLEV VEHICLE ALONG STRAIGHT AND CURVED SECTIONS OF A PLANE TRACK STRUCTURE
}

Institute of Transport Systems and Technologies of the National Academy of Sciences of Ukraine 5 Pisarzhevsky St., Dnipro 49005, Ukraine; e-mail NAR@westa-inter.com

Based on the solution of differential equations of motion for the vehicle of the unconventionally designed maglev system developed, which features four lines of superconducting magnets on the vehicle and two lines of track contours laid $1 \mathrm{~m}$ apart on a plane track structure, the vibrations of the vehicle and the stability of its levitated motion along straight and curved track sections of constant and variable curvature are estimated. The aim of this paper is to work out recommendations for the development of a new maglev system. The novelty lies in that a plane track structure and two lines of track contours can be used in the maglev system. It is shown that at appropriate values of the basic parameters of the system the vehicle exhibits a stable levitated motion in straight track sections in a wide range of speeds, while for curved track sections the speed is limited by the admissible lateral acceleration of the vehicle body. The advisability of using the maglev system developed is demonstrated.

Kлонвые слова: motion stability, vibration, plane track structure track curvature, maglev transport system.

1. Voroshilov A. S., Guba T. L., Zvonareva O. V., Radchenko M. O. On the choice of advisable designs of maglev transport systems with a plane track structure. Teh. Meh. 2012. No. 4. Pp. 8-12. (in Russian).

2. Shakhuniants G. M. Railway Track Moscow: Transport, 1969. 536 pp. (in Russian).

Received on July 26, 2017, in final form on October 10, 2017 